\title{
Impact of Fire Disaster Risk Preparedness in Prisons Departments in Central Kenya
}

\author{
N. E. Cheruto, E. M. Neyole, and R. Simiyu
}

\section{ABSTRACT}

\begin{abstract}
Across the world, prisons have suffered severe damage as a result of natural and man-made disasters including fires and deaths of inmates inside the prisons. The worst and most threatening disasters in prisons are the fire that may eventually lead to either deaths or prisoners escaping. Following the prevailing circumstances in the Kenyan prisons over a period of between 2010-2015, the current study sought to evaluate the impact fire disaster preparedness in prisons in Central Kenya. Specifically, the study examine magnitude of fire disaster risks in prisons in Central Kenya. The study employed a descriptive research design. Simple random sampling was used in the selection of prisons officers since the population was largely heterogeneous. Simple random sampling was then used to select prisons officers at the management level. The study targeted a population of 234 respondents who at the management level. Prison officer in charge, National Disaster Operation centre representative and inmate leaders were used as key informants. Data were collected using structured questionnaires and interview guides. The quantitative data were analysed using descriptive and inferential statistics while qualitative data were analysed using content analysis and thematic analysis. The research findings were presented in tables and figures. The study result show that Kenyan Prisons face significant fire disaster risks as noted by $90 \%$ of the respondents. Infrastructure to prevent fire incidents was only at $32 \%$; only $21 \%$ felt that there were escape routes in prisons, which made it difficult for prisoners to escape during fire disasters. High walls were a deterrence for prisoners to escape as well $(56 \%)$. The study concluded that the prisons lacked fire safety management protocols; the infrastructure from the surveyed prisons were not fire safety compliant. It is recommended that the Kenya Prison Service should endeavour to enhance prison fire safety by investing in installing and designing effective infrastructure.
\end{abstract}

Keywords: Disaster, Fire Management, Preparedness, Prison, Fire Disaster Risk
Published: January 21, 2022

ISSN: $2593-8339$

DOI: $10.24018 /$ ejmed.2022.2.1.186

\section{N. E. Cheruto*}

Masinde Mulito University of Sceince and Technology, Kakamega, Kenya

(e-mail: eddahcheruto10@yahoo.com) E. M. Neyole

School of Disaster Management and Humanitarian Assistance, Masinde Muliro University of Science and Technology, Kakamega, Kenya.

(e-mail: mneyole ${ }^{@}$ hotmail.com)

R. Simiyu

School of Disaster Management and Humanitarian Assistance, Masinde Muliro University of Science and Technology, Kakamega, Kakamega County, Kenya.

(e-mail: naliaka@ yahoo.com)

*Corresponding Author

\section{INTRODUCTION}

Prison fires have a long history of destruction and fatalities globally; where overcrowding has been a born of contention (Valcik NA, Tracy, 2017). It is known that in 2012 Comayagua Prison fire in Honduras claimed 360 inmates and their visitors. The prison unrest is also the precursor for prison fires such as the 2016 Guyana fires claiming 17 inmates (Anderson, Ifill, Adams \& Moss, 2020). Ignorant of the dangers of fire increases exposure to fire risks and is the determinant of the management capacity to prevent and detect potential exposure and vulnerabilities in the prison system (Horváth \& Kalamár, 2018).

In Africa, major examples of prison fires that have occurred in the recent past include the 1998 Kitwe Prisons fire tragedy in Zambia where several inmates were injured. In 2016, Ethiopian Qilinto remand prison fire claimed the lives of 21 inmates by suffocation and two out of the prison stampede (Schemm, 2018).

In Kenya, most penal institutions are not prepared for disasters whenever they strike (Mulinge, 2016). Prison fires have a serious history of destruction, i.e., the 2009 Langata prisons fires which razed down the entire staff block with properties worth millions of shillings destroyed. Kenya's prisons have failed to put in place a comprehensive disaster preparedness policy; response to high-risk fire disasters thus has remained slow, poorly coordinated and unnecessary expensive (Gicheru, 2011). Meru prisons fire in 2012 destroyed the prisons industry estimated at 2 million shillings. Again, in 2015, Meru prisons fire resulted in an inmate's death, 3 injuries and loss of properties (CGP Report, 2015). The Kenya Prisons, between January 2013 and January 2015, prison departments have recorded more than twenty fire incidents (Mulinge, 2016). In the year 2016 alone, seven (Gicheru, 2011) fire outbreaks have been reported (Mulinge, 2016). This study, therefore, established the impacts of fire 
disaster preparedness in prison departments in Central Kenya.

\section{Problem Statement}

From all these episodes, there seems to be no action taken by prison authorities worldwide to avert the situation. There is actually a discrepancy between the frequency of fire disasters and the level of prisons disaster preparedness. In fire disaster situations, the main responsibilities of the response teams are to save lives, reduce permanent disability, provide basic medical services to the injured, and reduce the risk of disease and death due to suffocation or burns. These responsibilities can only be carried out if the disaster response teams have the right equipment and the right expertise to deal with this situation or av ert such disasters from occurring. These incidents continue to recur without proper frameworks for mitigating these outbreaks. The prisons staff are affected equally as the inmates. Loss of lives and loss of properties worth millions of shillings have been caused by these fire outbreaks. This shows that there is a problem with fire disaster preparedness in the Kenyan prisons facilities upon which if not well addressed, the prisons department will continue to incur losses of properties and lives. It is against this background that the study sought to evaluate the impact of fire disaster preparedness in Prisons in Central Kenya.

\section{CONCEPTUAL FRAMEWORK}

\begin{tabular}{|c|c|c|}
\hline \multirow{5}{*}{$\begin{array}{l}\text { Preparedness strategies } \\
\text {-Training on disaster management } \\
\text { - Fire drills schedule } \\
\text {-Presence of fire safety tools } \\
\text {-Prisons disaster management } \\
\text { committee } \\
\text { Allocation of resources } \\
\text { (infrastructure, Financial, human) } \\
\text { Early warning system }\end{array}$} & & \multirow{4}{*}{\begin{tabular}{l}
\multicolumn{1}{c}{ Dependent Variables } \\
Fire disaster response operations \\
in Kenya Prisons Service \\
-Swift evacuation \\
-Coordination during fire disasters \\
-Fire disaster prevention
\end{tabular}} \\
\hline & & \\
\hline & & \\
\hline & $\begin{array}{l}\text { Intervening Variables } \\
\text { Bureaucracy in Leadership } \\
\text {-Organizational policies and }\end{array}$ & \\
\hline & resources & \\
\hline
\end{tabular}

Fig. 1: Conceptual framework

\section{MATERIALS AND METHODS}

The study area was the Central Kenya region with particular attention to prisons. The study used a cross-sectional research design with both quantitative and qualitative methods. According to the type of data that was needed at one point in time and with many variables investigated, cross-sectional design was preferred. This was able to provide the much-needed data on the impacts of fire disaster risk preparedness in the Kenyan prisons environment. The study's target population was prison management because this cadre had the relevant knowledge on fire disaster risk preparedness and the fire disaster risks in prisons. Key informants comprised Prisons' officers-in-charge, inmate leaders and the national disaster operation centre representative (NDOC). The study area had a target population of 234. Simple random sampling was used to determine the sample size for this study which was $40 \%(\mathrm{n}=94)$ (Mugenda \& Mugenda, 2003). Data was collected using a structured questionnaire. Purposive sampling was used to select key informants whose interviews triangulated the main data from the prisons officers. The impact of fire disaster risk preparedness was obtained. Research assistants were recruited and trained for three days and they assisted in data collection.

The collected data were coded and entered into the computer for analysis with the aid of the Statistical Package for Social Sciences (SPSS) version 25. Descriptive statistics were presented in figures in form of proportions. Key informant data were reported in verbatim format. Ethical clearance was obtained from the Institutional Ethics and Review Committee of Masinde Muliro University of Science and Technology and the National Commission for Science, Technology, and Innovation.

\section{RESULTS}

\section{A. Demographic Characterization of the Prison Officers}

Socio-demographic characteristics were investigated and showed that $79 \%$ of the respondents were youthful; the study had $55 \%$ male and $45 \%$ female participants. About $50.6 \%$ of the prison officer had post-secondary education. Also, $78 \%$ of the participants had worked in prison service for more than five years.

\section{B. The Extent to Which Existing Risk Exposures Impacts Preparedness Levels}

\section{Prevalence of Fires in Prisons}

The researcher sought to establish whether prison fires were rampant in prison facilities. This was sought from the 
determination of the prevalence of fires in prisons in Central Kenya. Fig. 1 illustrates the findings.

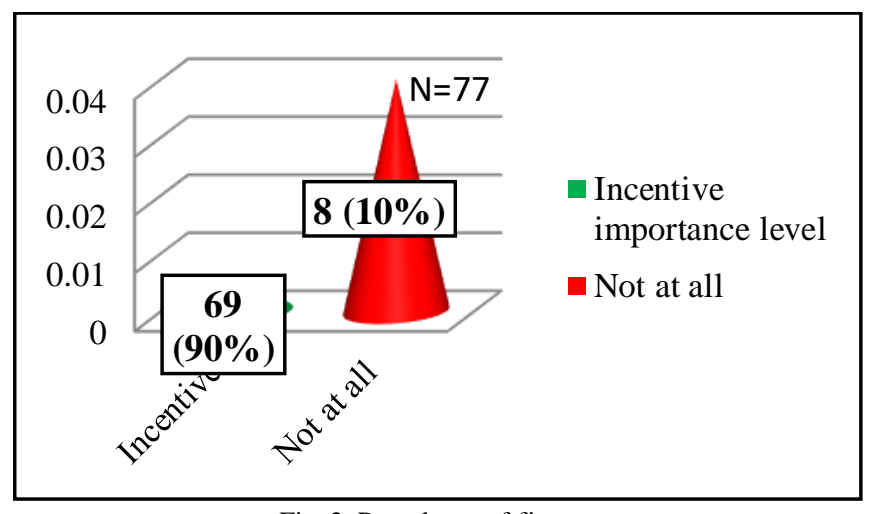

Fig. 2: Prevalence of fires

According to Kenya Prison Officers interviewed (Fig. 2), 90\% confirmed that there were occurrences of fires in prisons. Key informants 3 (prison in-charge) indicated in a statement that:

... prison buildings are lacking fire escape doors (routes) and fire alarm call points.

Moreover, another key informant 1 (prison in-charge) stated that:

... there is no disaster committee or a crisis team in our prison. Besides, we know that prisoners have no right to free movement that is why there are high walls in the prisons dormitories. It is an exposure to fire risks in case of one; inmates cannot escape unless my officers are prompt in saving them.

Key informant 2 (prison in-charge) added that:

... There is limited space in the prisons, overcrowding in the prison cells exposes the prisons to a lot of risks, especially fire risks. However, we have fire extinguishers and water points and pipes, but you know the inmates are rarely trained on how to react or use these tools in case of fire. This is a risk according to me."

Moreover, the findings were supported by key informant 7 from NDOC who stated that:

... prisons are ill-prepared to handle fire emergencies. This is due to facilities incapacities."

From the observation checklist, the researcher noted that there were grills and concrete walls as well as electric fences in all the surveyed prisons. It was also observed that there were fire extinguishers strategically positioned, backed by horse reels and water points in all the surveyed prisons.

\section{The extent of prison fires}

Owing to the aforementioned prevalence of prison fires, the researcher investigated the extent of prison fires that impacted disaster preparedness. The five-point Likert scale was used to establish the extent level of prison fires as very low extent, low extent, moderate extent, great extent and very great extent. The results are shown in Fig 3.

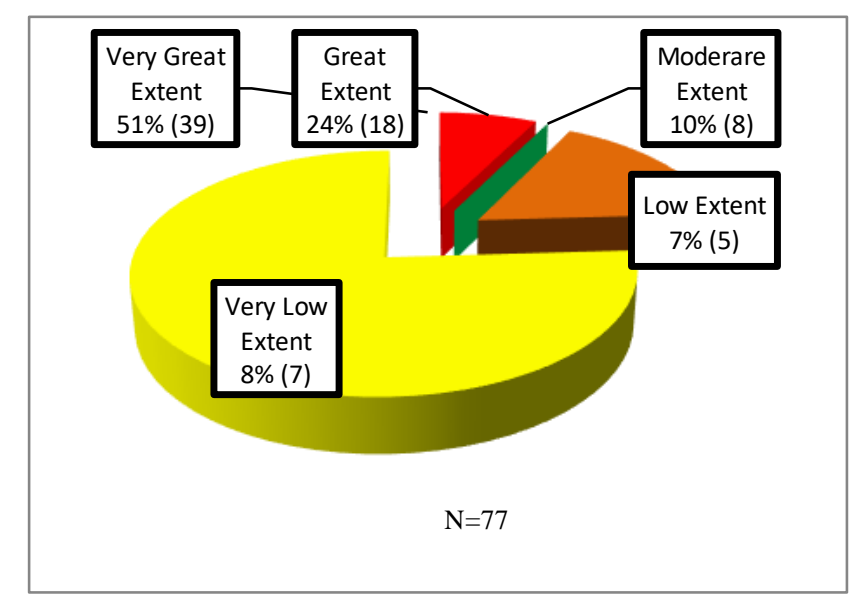

Fig 3: Extent prison fires impacting on disaster preparedness levels 
According to the surveyed Kenya Prison officers (Fig. 3), 75\% of the prison officials were in agreement that there was a great extent and the very great extent of prison fires that impacted the prisons' preparedness levels. It can be drawn from the findings that the prisons are highly susceptible to loss of lives and property in an event of a fire disaster hits.

Key informant 5 (inmate) stated that:

... there is an inherent lack of commitment and laxity by the prison top management in fire preparedness measures and investment especially human resources competent in fire safety management.

Key informant one (prison in-charge) also showed that:

... The blame game is an order of the day by the administrative organ of the prisons that always shifts blame to junior prison officers in the event of adversity in the prisons. This could not be different with fire disasters.

\section{Infrastructure to Curb Fire Disasters in Prisons}

The study investigated the infrastructure of the available prison designed to control fire disasters. A five-point Likert scale was used to establish the level of agreement concerning the infrastructure available. The findings are shown in Fig 4.

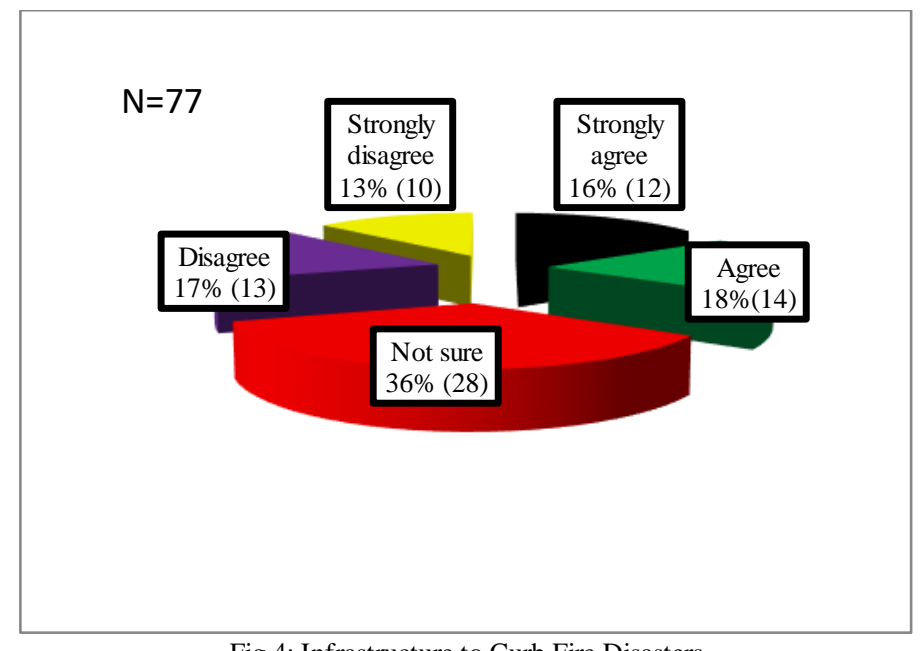

Fig 4: Infrastructure to Curb Fire Disasters

According to the Kenya prison officers surveyed (Fig. 4), only 32\% agreed and strongly that there was infrastructure to curb fire disasters in the surveyed prisons. Moreover, $36 \%$ of the surveyed prison officers were not sure that prisons had infrastructures to curb fire disasters.

Key informant 2 (prison in-charge) triangulated the findings by stating that:

...Prisons in Kenya have many challenges revolving around budget deficits, shortage in personnel and equipment for fire disaster preparedness and overcrowding.

An inmate key informant stated that:

... The building here is squeezed in bad shape. How do you become fire prepared you know? Something must be done by the Kenya Prisons Services and the Ministry of Interior to address the poor conditions in prisons.

Furthermore, key informant 7 (NDOC) added by stating that:

... the prisons are old buildings inherited from the colonial masters. At the time, they were never meant to correct vices but punish loyalty. Thus, they had no disaster management measures in place to take care of the prisoners.

\section{Prison Fire Risk Factors}

It was essential for this study to establish the fire risk factors that might be associated with prison fires in Central Kenya. The researcher, therefore, investigated the escape routes and high walls in prisons in Kenya.

\section{Escape Routes}

The study sought to establish whether there were escape routes for prisoners in case of fire disaster incidents. This was done by using a five-point Likert scale measuring agreement levels on the availability of escape routes for prisoners to escape in case of a fire incident. The findings are shown in Fig 5. 


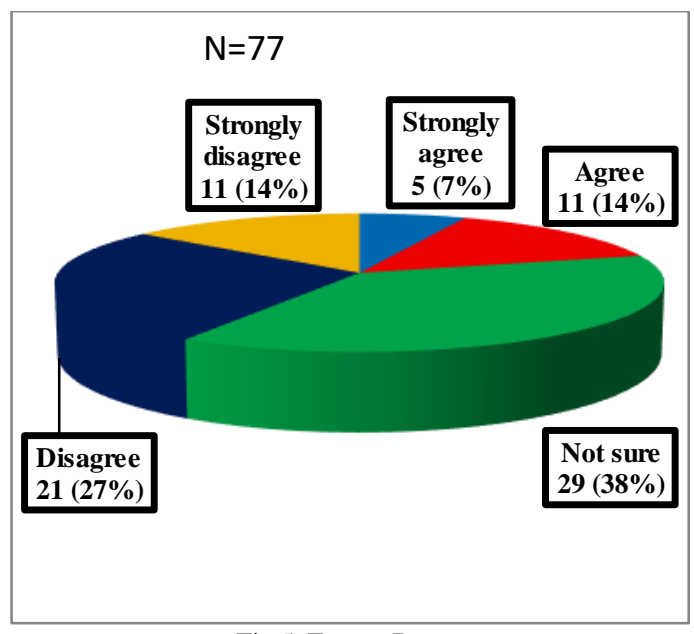

Fig 5: Escape Routes

According to the Kenya Prison Officers survey (Fig. 5), only 21\% agreed and strongly agreed that there were fire escape routes from prisons for prisoners. However, $38 \%$ were not sure that there were fire escape routes for prisoners.

Key informants 2 stated that:

... not only are inmates at risk of fire disasters because of a lack of escape routes, but also officers are similarly at risk considering to design of prisons, the prison staff have insufficient escape routes to aid escape during fire disasters.

Whereas key informant 3 stated that:

... These anti-escape features cannot be re-designed or alternatives be put there. That is primary. The only thing we can do about the risk of fires is to prevent them from occurring.

NDOC key informant 7 stated that:

... it is our mission as mandated by an act of parliament of 1998 to ensure we monitor, coordinate, make resources available during disasters and recoveries. Which we endeavour to do as a centre.

Key informant 1 stated that:

... most prison facilities - like ours at the moment - lack some of the essential safety equipment's which can be used to sense and warn people during fire disasters which increase chances of survival.

It was found out that anthropogenic elements are the main cause of fire risks in Kenya prisons, an account affirmed by a key informant that stated that

...We have had instances of fire outbreaks due to prisoners feeling aggrieved.

An inmate key informant echoed the feelings of the inmates stating that:

... There are times when the prison management violates their professional codes of conduct and mistreat us. Pressure builds up among inmates have led to prison riots and strikes which have been costly in terms of lives lost and property.

\section{High Walls Are Barriers to Evacuation During Fire}

The study investigated the influence of high walls on prisons fire risks among the prisoners. This was done by measuring the agreement levels of whether the high walls greater than 10 metres made evacuation difficult. The findings are shown in Fig 6. 


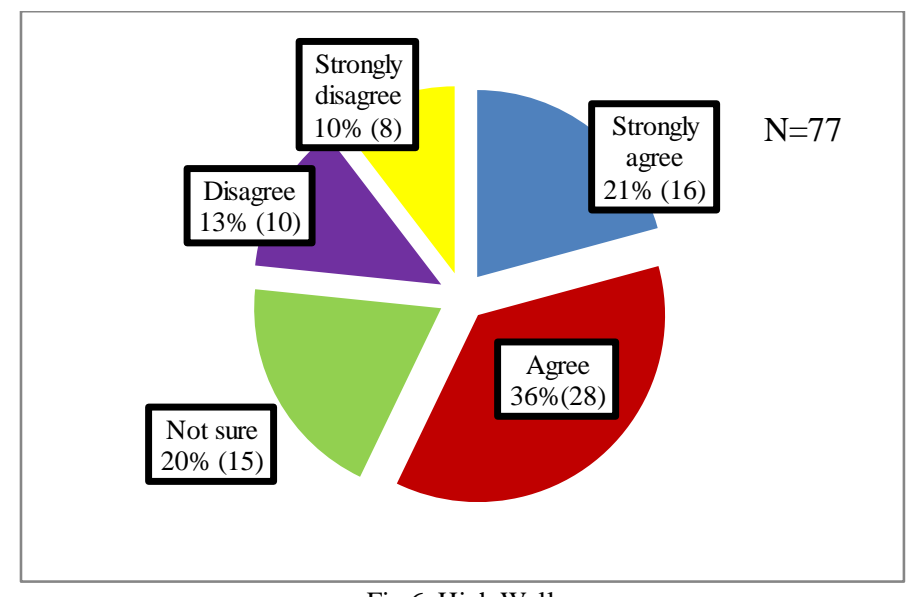

Fig 6: High Walls

According to the Kenya Prison officer survey (Fig. 6), 56\% agreed and strongly agreed that high walls in prison made it difficult for prisoners to escape during fire disasters in prisons. Key informant 3 stated that:

... The huge and electrified/secured prison walls make it difficult for the prison occupants to escape fire outbreaks. The prisons are not made for escape but containment until one is permitted by law to the prison.

Key informant 6 (inmate leader) stated that:

... Yes, we know we are condemned because of societal menace and we are prisons to answer to crimes and be corrected for the wrong that we have done. But, in the face of a disaster such as fire, the facilities should be made accommodative at least for ease of evacuation to other safe locations within the confines of prisons.

It was observed by the researcher that there existed high walls that contributed to high and eminent risks in terms of inmates not being able to escape in case of fire outbreaks due to the high electrified walls of the prisons.

\section{DISCUSSION}

Despite the level of preparedness regarding fire extinguishers and hose reels, there is still high fire risk exposures to pri soners in Kenyan prisons emerging from the administrators for being insensitive and lacked commitment towards disaster preparedness lack of goodwill which is in line with KHRC (2016) report. The design of this facility is in such a way that in case of fire, those inside the cells and cubicles will have no easy way out. This is because of the grills and concrete walls meant to ensure security and deter escapes.

\section{A. The Extent of Prison Fires}

This study found out that the top management in the prisons was never after the status quo and thus contributed to poor preparedness levels across the ranks and departments in the prisons hence increasing fire exposure risks to the prisons and prisoners. This study concurs with Gordon (2013) that negligent actions experienced in the past yielded severe disasters, key amongst them being; the 1946 Atlanta-Georgia (Winecoff Prisons) fire disaster that saw both inmates and prison wardens jump out of windows to their deaths.

\section{B. Infrastructure to Curb Fire Disasters in Prisons}

This is in support of UNDP (2009), that one of the key priorities in disaster management is sufficient infrastructural development that is hinged on the allocation of a budget on preparedness levels in prisons. It is known that disasters are difficult to predict; putting a speculative number in the budget may reduce the budget's credibility and usefulness (Phaup \& Kirschne, 2010). Having about $30 \%$ of the prison officers not agreeing and $36 \%$ not sure of the availability of infrastructures to curb fire disasters in Kenyan prisons surveyed, it concurs with the previous study by Adero (2016) that public institutions are faced with an avalanche of challenges in managing fire disasters.

The researcher observed that the installed fire extinguishers were not services; hence there were not effective in fire disaster management as prescribed. Adero (2016) maintains that fire department response capability and capacity is a function of resource allocation and is a significant determinant in the degree of vulnerability of a community to unwanted fires and other emergencies. Effectively managing these challenges requires a basic understanding of how changes in levels of fire department resources deployed affect outcomes from emergencies that occur daily. Failing to manage these challenges leave individuals, a fire department and a community vulnerable to undesirable events.

The findings of the current study are in agreement with Hirschler (2001) survey of 54 jails in one State revealed that $61 \%$ had no second means of exit from the housing area, $28 \%$ had no fire and smoke alarm detection system, and $41 \%$ conducted 
no fire drills. These figures reveal a state of neglect in correctional facilities not only in Kenya but also in the developed world. Correctional personnel must plan, implement, and monitor an effective program to reduce the chances of fires and to respond swiftly to actual emergencies. The next section sought to examine the subject of escape routes and their significance in disaster preparedness and risk reduction in Central Kenya's correctional facilities.

\section{Prison Fire risk Factors}

\section{Escape Routes}

According to Murao (2008), the architectural designs should accommodate disaster risk reductions measures; construction design in populous areas should consider the need to prevent the spread of fires and resettlement sites for victims of fire disasters. This study finds show that the prisons in Kenya do not enjoy the populous architectural and structural designs hence exposing the prison officers and prisoners to fire disaster risks. These are manifested from the insufficiency of escape routes and difficulties for prisoners to escape in the event of fire emergencies which all have to do with the traditional designs the current prison facilities still maintain. World Health Organization (WHO) suggested that safety is an indispensable element for maintaining a high quality of life as well as health, efficiency, and comfort (Charleson \& Taylor, 2004). This study recorded that in the surveyed prisons, the management had overlooked the concept of fire safety management and fire disaster preparedness in order to improve safety in their areas of jurisdiction. This was in line with (Savilonis, 2014) that prisons are not prepared to respond to and recover from disasters. Fire spread can be curtailed from a proper prison design that consider s fire escape routes and exists as alluded to by Iyaji, Kolawole \& Anthony (2016) that the design and construction play a significant role in fire disaster management.

The lack of involvement in DRR strategies is evidence enough of their marginalization in Central Kenya Prisons. With the majority of prisons across the country facing limited funding, staffing shortages, and a lack of resources- correctional facilities across the country will remain unprepared to respond to and recover from disasters, failing at their duty to protect prisoners, as well as members of the public. Lack of escape routes for prisoners is the thin line between life and death; of which $51 \%$ of the surveyed prison officers stated that the prisoners would not escape in the event of a fire disaster.

Disasters can lead to a violation of prisoners' constitutional and statutory rights and pose several types of injury (physical, emotional, mental, health), as well as public safety risks and legal risks. There is a broad spectrum of concerns when respon ding to and recovering from disasters at prisons. Specific concerns include the standards of care for prisoners, the dispersion of prisoners, records management, and staffing shortages. The next section sought to establish whether prisoners were faced with difficulties to escape from fire disasters.

Information derived from the checklist confirmed that there were electric fences around and in some quarters of the prison. Additionally, steel grills had been erected to reinforce doors and windows, with concrete walls surrounding the whole prison and the cells. From the data collected, there were first aid kits; however, these kits were stored at the clinic or infirmary and not strategically placed within the facility. From these findings, the study established that the risk of fire disasters was eminent. These findings are consistent with those of Karanja and Nyambura (2010) where they highly ranked security concern (65.3\%) as a priority issue of KPS followed by safe containment offenders. These findings are still consistent with Bukoski (1996) who established that most buildings are constructed with metal grills that are aimed at preventing robbers/burglars from gaining access to the house, minding less on creating escape routes in the event of fire disasters.

This was triangulated by an observation checklist which noted few fire detectors and smoke detectors in the prisons visited, with some of them not functioning. The study noted that fire alarms were in place in all the prison facilities; however, the researcher could not authenticate whether they were functioning or not, as setting them up during the research time could trigger tension among the inmates. It was also established even the firefighting equipment (fire extinguishers, EWS and smoke detectors) are procured only occasionally and that some of the fire extinguishing cans that are strategically placed in strategic locations of the prisons buildings are shabby and rusty, meaning that they are either expired or doesn't contain the content (foam/powder) it is purportedly supposed to have. Again, it emerged that most prison stations did not have in place lighting arrestors, smoke detectors or even fire alarm call points.

An empirical study on reducing and managing disaster risks in prisons and jail in the Philippines through interviews with prison management and inmates as well as prisoner leaders established that preventing hazards is a difficult task at the scale of jails and prisons and rather fall under the responsibility of local governments- except fire disasters (Gillard et al., 2020). The Kenya Prisons top management requires to ensure disaster risks are management promptly in order to mitigate against causalities should a fire disaster hit.

The findings of the current study are in agreement that the traditional prison designs in Kenya have outlived their usefulness in terms of disaster management and therefore, existing prison facilities have to be structurally modified to ease disaster risk reduction (DRR). In addition, the current study advocates that new development of correctional facilities should accommodate disaster resilient features to protect the inmates and the prison officers in the event of hazardous events. The current study concurs with Gilliard et al. (2016) that inmate coordinators should contribute to disaster risk assessment and DRR plans to be designed by jail and prison DRR officers provided that all other security concerns are addressed. Jail and prison DRR officers should provide inmate/prisoner DRR coordinators and all inmates with relevant information on DRR. The findings of the current study disagree that inmates were active participants in DRR strategies. Lastly, DRR should be incorporated in the Kenya Prisons training curriculum.

Escaping from prisons during fire disasters is a nightmare globally. In 1930, a prison fire in Columbus, Ohio, in which 300 inmates died (Wrightstyle, 2016). Having been built in 1834, and in poor structural condition, a minor fire on some external 
scaffolding spread to the building's roof causing its eventual collapse. The fire led to the reform of laws on minimum sentences that had partially caused the prison's overcrowded conditions. Overcrowding in Kenya Prisons is not a new phenomenon, which according to this study it is making it difficult to evacuate in times of fire disasters, thus leading to damages and sometimes loss of lives of both prisoners and the prison staff. It is known (Owino, Egesah, Akong'a, 2015) that prison conditions in Kenya have for a long time been characterized by overcrowding, congestion, poor diet, degrading clothing and bedding, lack of clean water, poor sanitation and infectious diseases amongst other challenges.

In the past six years, over 1714 inmates have died in prison with the largest death of 623 being reported in 2013. A recent study by KHRC (2016) on the Criminal Justice System in Kenya suggested that the predicament of overstretched social amenities predisposes prisoners to epidemic outbreaks. Moreover, the KHRC (2016) report urged the Government of Kenya to adopt the Ouagadougou Declaration and plan of action on accelerating Prison and Penal Reforms in Africa. This declaration is anchored on a number of pillars such as reducing the prison population, looking towards the United Nations Charter on the Basic Rights of Prisoners and adherence to the rule of law among others. Based on the findings of the current study, it is prudent to point out that prison facilities in Central Kenya are not only faced with emergency issues of fire outbreaks but also spread of communicable diseases, overcrowding which may lead to a stampede during sudden onset emergencies among other hazards.

\section{High Walls are Barriers to Evacuation during Fire}

This study was in line with Den (2018) study that the architectural and structural designs of the matter of the prison for the safety of the prison staff and inmates. The findings of the current study revealed outstanding gaps in prison designs and their relevance in disaster management. To this end, disaster risk reduction efforts ought to take into account the nexus between architectural design and disaster management. To this end, therefore, enlightening housing developers and users about fire, the occurrence, spread, hazards and havocs, and motivating them that through users' prudence, efficient designs, specification and construction management, the impacts of fire on lives and property could be minimized Tartaro \& Levy (2017) argue that the design of prisons ought to take a transformative approach into less traditionally designed institutions to more normalized and conventional designs as this could be beneficial in terms of reducing suicides. The findings of the current study do not concur with Tartaro \& Levy (2017) as the current prison facilities in Kenya were designed in the colonial and early post-colonial periods and thereby did not take into consideration emergency issues in design. It was ascertained that the surveyed prisons failed to take into consideration the emergency contingency needs of prisoners should unexpectedly events of fire disasters arise. This is contrary to Wener (2017) study that prisons with layouts that support direct contact between staff and inmates showed more beneficial outcomes. Overall, Den (2018) argued that factors such as noise, lighting, windows, green spaces and temperature should be taken into consideration. The current study argues that in as much as Den (2018) did not explicitly link the aforementioned parameters to the emergency, they are essential and partly serve the humanitarian aspect of ensuring the welfare of inmates as well as prison officers.

The findings of the current study agree to a large extent with Brand (1995)Error! Reference source not found. that the risks of disasters and their impact on the built environment can be mitigated through a disaster sensitive approach to construction, planning of settlements, maintenance and reconstruction. This is known as DRR Architecture and Planning, the Disaster-Resistant Approach to the Built Environment or, simply Adaptive Architecture. Adaptive architectural solutions contribute to directly protecting lives through the provision of safer houses, for example, in the case of non-engineered dwellings; Directly protecting lives during and in the aftermath of an emergency, through transforming basic infrastructure (schools, kindergartens) into safe havens; Directly saving economic and physical assets from the effects of disasters; Indire ctly saving economic assets through Building Back Better after disasters, so as to mitigate the risk of occurrence in the future; and Indirectly sustaining the effort of sustainable development, by avoiding disruption of social, economic, cultural and educational activities of societies (Wamsler, 2014).

\section{CONCLUSION}

The study established that the surveyed prison lacked fire safety management protocols both physical and human capacity. The infrastructure was not designed to aid fire risk especially cells with high walls some barricaded with electric fences to contain the inmates hampers escape in case of fire episode. The bottom line is the nature of the prisons infrastructurally promoted fire risks in Kenyan prisons.

\section{RECOMMENDATION}

Kenya Prison Service should endeavour to enhance prison fire safety by investing in installing and designing an effective infrastructure that would both prevent prison escape and allow rescue when a fire emergency occurs.

\section{ACKNOWLEDGEMENT}

The achievement of this thesis has been as a result of many people as acknowledged herein, I would like to thank them for their sincere and devoted efforts, advice, moral and financial assistance which saw the successful completion of the research 
project. Special gratitude goes to my Supervisors Prof Edward Masinde Neyole and Dr. Ruth Simiyu who tirelessly ensured that this thesis was done as per the requirements, sacrificed their time in guiding me while developing this thesis. I thank the Ministry of Interior and Coordination of National Government, State Department for Correctional Service, Kenya Prisons Service for allowing me to use the facility in collecting data, use the office equipment and allowing in documenting the internal information of the facility. My research assistant Mr. Otieno for delivering in the correctional setting as well as assisting me with data analysis. Special thanks go to my husband James Kioko for his patience, advice and prayers, encouragement even when there seemed to be no light at the end of the tunnel due to life challenges, my classmates for the assistance the y rendered. Above all I give thanks to God for granting me good health throughout my study, helping me to achieve and finish this great work.

\section{CONFLICT OF INTEREST}

Authors declare that they do not have any conflict of interest.

\section{REFERENCES}

Adero, M. (2016). Fire Disaster Mitigation and Preparedness in Nairobi: a Capacity Assessment of the City's Fire Brigade [Unpublished doctoral dissertation]. University Of Nairobi.

Anderson, C., Ifill, M., Adams, E., \& Moss, K. (2020). Guyana's Prisons: Colonial Histories of Post-Colonial Challenges. The Howard Journal of Crime and Justice, 59(3), 335-349.

Brand, S. (1995). How buildings learn: What happens after they're built. Penguin.

Bukowski, R. W. (1996). Risk and performance standards.

Charleson, A., \& Taylor, M. (2004). Earthquake architecture explorations. In Proceedings of the 13th World Conference on Earthquake Engineering (pp. 596-599). The Canadian Association for Earthquake Engineering.

CPG Report (2015, May). Disaster Management and Mitigation Unit, (2004). Impacts of the 2004 Northridge Fire Disaster. Santa Monica Business Study.

Den, B. (2018). How Architecture and Design Matter for Prison Services: A Rapid Review of the Literature. Research and Evaluation Unit: Swedish Prison and Probation Service; Norrköping.

Gaillard, J. C., Casing-Baring, E. M., Sacayan, D., Balay-as, M., \& Santos, M. (2020). Reducing and managing the risk of disaster in Philippine jails and prisons. Emerald Open Res, 2(54), 54.

Gicheru, C. (2011, October). These disasters can be averted. Daily Nation, Nairobi: Nation Media Group.

Gordon, M. (2013). Exploring existing methodologies for allocating and tracking disaster risk reduction in national public investment. Background Paper prepared for the Global Assessment Report on Disaster Risk Reduction. UNISDR.

Hirschler, M. M. (2001, June). Fire Safety in Detention Environments. In Fire Risk \& Hazard Assessment Symposium, Fire Protection Research Foundation (pp. 241-273).

Horváth P., \& Kalamár N. (2018). Investigating the level of fire safety at prisons in Hungary. Ambientum. 33.

Iyaji, S. O., Kolawole, O. B., \& Anthony, A. T. (2016). The role of design and construction in mitigating fire disasters in housing in Nigeria. Journal of Good Governance and Sustainable Development in Africa, 3(1), 73-84.

Karanja, J. N. (2010). How to initiate evacuation movement in public buildings Facilities. Vol. 17, pp. 331-5.

KHRC (2016). Government of Kenya (GoK). Kenya Prisons Disasters Report.

Mugenda O. M. \& Mugenda A. G. (2003). Research Methods: Quantitative and Qualitative Approaches. Nairobi: Acts Press.

Mulinge, D. N. (2016). An assesment of internal factors affecting public relations performance in the Kenya prison service: a case of prisons in Nairobi region [Unpublished doctoral dissertation]. University Of Nairobi.

Murao, O. (2008, October). Case study of Architecture and Urban design on the disaster life cycle in Japan. In 14th World Conference on Earthquake Engineering Proceedings.

Owino, B. O., Egesah, O. B., \& Akong'a, J. J. (2015). Looking in the mirror: reflections on implementation of the principles of penal system in Kenya's prisons.

Phaup, M., \& Kirschner, C. (2010). Budgeting for disasters: focusing on the good times. OECD Journal on Budgeting, 10(1), 1-24.

Savilonis, M. A. (2014). Prisons and disasters [Unpublished doctoral dissertation]. Northeastern University.

Schemm, P. (2018, July). Ethiopia fires prison officials over human rights abuses amid torture reports. The Washington Post.

Tartaro, C., \& Levy, M. P. (2008). Predictors of suicide in new generation jails. Justice research and policy, 10(1), 21-37.

UNDP (2009). Urban Risk Management. New York: UNDP Bureau for Crisis Prevention and Recovery.

Valcik, N. A., \& Tracy, P. E. (2017). Case studies in disaster response and emergency management. Routledge.

Wamsler, C. (2014). Cities, disaster risk and adaptation. Routledge.

Wener, R. (2012). The environmental psychology of prisons and jails: Creating humane spaces in secure settings. Cambridge University Press.

Wrightstyle, K.(2016). Escaping Prison Fires Through Design. Steel Glazing Systems-UK.

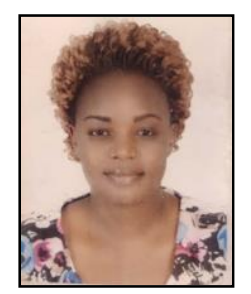

Ngeywa Eddah Cheruto is a correctional officer in charge of mentorship in Central Kenya. She is an enthusiastic scholar. She has amassed a wealth of knowledge in human behaviour. She is a graduate student of Masinde Muliro University of Science and Technology with a Masters Degree in Disaster Management and Humanitarian Assistance. Her research interests were in the Kenya prison environment that is exposed to fire disaster risks. 